\title{
1 Sensory plasticity in a socially plastic bee
}

\section{Rebecca A Boulton ${ }^{\star 1,2}$ and Jeremy Field ${ }^{3}$}

$3{ }^{1}$ Laboratory of Genetics, Plant Sciences Group, Wageningen University \& Research,

46708 PB, Netherlands

$5 \quad{ }^{2}$ Biological and Environmental Sciences, University of Stirling, FK9 4NF, United

\section{Kingdom}

$7 \quad{ }^{3}$ College of Life and Environmental Sciences, University of Exeter, Penryn campus,

8 TR10 9FE, United Kingdom

9 *author for correspondence: rebeccaboulton87@googlemail.com

\section{Abstract}

12 The social Hymenoptera have contributed much to our understanding of the

13 evolution of sensory systems. Attention has focussed chiefly on how sociality and

14 sensory systems have evolved together. In the Hymenoptera, the antennal sensilla

15 are important for optimising the perception of olfactory social information. Social

16 species have denser antennal sensilla than solitary species, which is thought to

17 enhance social cohesion through nest-mate recognition. In the current study, we test

18 whether sensilla numbers vary between regional populations of the socially plastic

19 sweat bee Halictus rubicundus. We found region level differences in both olfactory

20 and hygro/thermoreceptive sensilla numbers. We also found evidence that olfactory

21 sensilla density is developmentally plastic: when we transplanted bees from Scotland

22 to the south-east of England, their offspring (which developed in the south) had more

23 olfactory hairs than the transplanted individuals themselves (which developed in

24 Scotland). The transplanted bees displayed a mix of social (a queen plus workers)

25 and solitary nesting, but neither individual nor nest phenotype was related to sensilla 
26 density. We suggest that this general, rather than caste-specific sensory plasticity

27 provides a flexible means to optimise sensory perception according to the most

28 pressing demands of the environment, and may support social plasticity in $H$.

29 rubicundus.

\section{Introduction}

37 Natural selection on sensory abilities has resulted in enormous diversity in the

38 mechanisms that organisms use to perceive their environment. For example, species

39 of Lake Tanganyika cichlids that have colonised more complex, rocky habitats have

40 greater visual acuity than sand-dwelling species (Dobberfuhl et al. 2005). These

41 mechanisms can also feedback into selective regimes, facilitating micro- and

42 macroevolutionary change through sensory drive. Sensory drive occurs when local

43 adaptation results in populations with diverging modes of communication and

44 perception. This has been proposed to lead to assortative mating between partners

45 with complementary signalling and perception systems, reducing geneflow and

46 promoting speciation (Boughman 2002).

48 The Hymenoptera have emerged as a model system to understand both the

49 proximate and ultimate factors that underlie sensory evolution. These insects have

50 antennal receptors with diverse functions and distinct forms that can easily be 
51 characterised within and between species. This work has revealed that both the

52 density and form of antennal sense organs (sensilla) correlate with diet (Polidori et

53 al. 2012; 2020), sex (Babu 2019; Do Carmo Queiroz Fialho et al. 2014) and a

54 cleptoparasitic lifestyle (Wcislo 1995; Galvani et al. 2017). Attention has focussed

55 particularly on how eusociality has imposed selection to optimise antennal

56 perception. Eusociality involves reproductive division of labour with a queen/s

57 producing eggs and workers provisioning the brood. However, sociality takes diverse

58 forms across the bees and wasps and group sizes vary enormously, providing rich

59 opportunities for comparative study. Many obligately social species show worker

60 polyphenism, where some workers specialise on brood care and others on foraging

61 or guarding the nest (Andersson 1984). Compared with solitary species, social

62 species require more finely tuned communication systems to distinguish intruders

63 from kin and gain information from nestmates (Wcislo 1997; Renner and Nieh 2008).

64 Across the Hymenoptera, social species tend to have greater densities of antennal

65 sensilla that are involved in the perception of olfactory cues than solitary species

66 (Elgar et al. 2018). This is thought to enhance social cohesion and performance by

67 facilitating nest-mate recognition (Ozaki et al. 2005; Gill et al. 2013; Couto et al.

68 2017) and supporting caste polyphenisms (Spaethe et al. 2007; Riveros and

69 Gronenberg 2010; Gill et al. 2013; Gru $\square$ ter et al. 2017; Elgar et al. 2018).

71 The olfactory antennal sensilla have been proposed as a pre-adaptation that acts

72 alongside haplodiploidy to predispose the Hymenoptera to the evolution of sociality

73 (Couto et al. 2017). A conserved, ancestral olfactory subsystem involving the

74 basiconic antennal sensilla has been suggested to facilitate kin selection by allowing

75 nestmate recognition from cuticular hydrocarbon (CHCs) profiles (Ozaki et al. 2005; 
76 McKenzie et al. 2016; Couto et al. 2017; Pask et al. 2017). While empirical evidence

77 for this subsystem exists for only two species (an ant and a hornet), the halictid bees

78 have also provided support for the possibility that sensory pre-adaptations might

79 contribute to the evolution of sociality. The Halictidae or sweat bees exhibit a range

80 of social structures, from solitary nesting through to obligate sociality, including

81 within-species social polymorphism and social plasticity (Gibbs et al. 2012). A

82 comparative study by Wittwer et al (2017) has shown that ancestrally solitary species

83 and their social sister species have equivalent densities of hair-like sensilla

84 (basiconic and trichoid sensilla) that detect olfactory cues. Species that have

reverted to a solitary existence from sociality on the other hand, have reduced

densities of these sensilla. This suggests that in the Halictidae, sensitivity to olfactory

87 cues precedes the evolution of sociality rather than evolving as a consequence of it.

89 In addition to caste polyphenisms, where individuals always form social groups but

90 vary in the tasks that they perform, a number of species are facultatively social. In

91 these species, individuals vary in their propensity to form social groups or nest as

92 solitary individuals (Gibbs et al. 2012). This social plasticity is thought to be key to

93 the evolutionary diversification of the Hymenoptera as it provides a genetic base

94 from which obligate eusociality and caste polyphenism can evolve repeatedly (West-

95 Eberhard 2003; Jones et al. 2017). It also provides an opportunity to test for

96 correlates of social evolution without the complication of interspecific differences. In

97 this study we characterise the antennal sensilla of a facultatively social species,

98 Halictus rubicundus, for the first time. We measure the density of different antennal

99 sensilla types between regional populations of this socially plastic sweat bee and test

100 whether sensory plasticity mirrors social plasticity in a transplant experiment. Our 
results represent an important step in disentangling the sequence of events that led

102 to the evolution of eusociality and reproductive division of labour in the

103 Hymenoptera.

\section{Materials and methods}

107 Study system

108 Halictus rubicundus is a ground-nesting bee that can be found throughout Europe

109 and North America in areas with sandy-loamy soil that receive sufficient sunlight. In

110 Great Britain and Ireland, $H$. rubicundus demonstrates social variation according to

111 latitude but retains social plasticity throughout its range (Field et al. 2010; 2012). In

112 the north bees are typically solitary as the short growing season and cooler climate

113 precludes the bivoltinism that is required for social living. In a typical year in the

114 north, foundresses produce a single brood of offspring per year, the females of which

115 enter hibernation and emerge to become foundresses the following spring (figure

116 1a). In the south, growing seasons tend to be longer and the weather is warmer, so

117 bivoltinism and sociality can occur more frequently. After overwintering underground,

118 females produce a first brood (the B1) which become workers and provision a

119 second brood (B2) which are offspring of either the original foundress or a B1

120 replacement queen. B1 females are also observed to provision their nests alone

121 (without workers) in the same year that they emerge. The B2 hibernate and emerge

122 the following year to found their own nests (figure 1b; Field et al. 2010; 2012).

124 Sociality is extremely plastic in H. rubicundus in Great Britain, and when solitary

125 northern bees are transplanted to the south, the B1 brood will often provision as 
126 workers or solitary foundresses in the same year (Field et al. 2010; 2012; this study).

127 Here we test for fixed and plastic differences in antennal sensilla density in $H$.

128 rubicundus across and within populations. We first test whether olfactory sensilla

129 densities differ between bees from southern populations, where the climate allows

130 some individuals to form social nests most years, and northern populations with

131 limited opportunity to form social nests. Second, we test whether antennal sensilla

132 numbers are developmentally plastic by transplanting bees from the north to the

133 south. Do the offspring of northern bees that develop in the warmer south have

134 different numbers of antennal sensilla than their parental generation which

135 developed in the north? We also test for differences in sensilla number between

136 individual and nest-level phenotypes: do social individuals/nests exhibit greater

137 densities of olfactory sensilla to aid in nestmate recognition?

139 Collection

140 Halictus rubicundus females were collected from 4 sites in the UK in 2018, 2019 and

1412020 (see fig 1c). Two sites in the south-west (SW): Boscastle (Cornwall: N 50 41'

142 24" W 4 41' 24"; N = 12; 2018) and Bodmin (Cornwall, N 50 30' 36" W 4 33' 36"; N

$143=4 ;$ 2019); a site at a mid-latitude (MID): Belfast (Northern Ireland, N 54 32' 24” W

$144 \quad 5^{\circ} 58^{\prime} 48$ "; $N=19 ; 2020$ ); and a site in the far north of Scotland (SCO): Migdale

145 (Scotland, N 57 53' 24" W 4 15' 0"; N = 15; 2018 and 2020). Previous studies and

146 our own observations indicate that while a proportion of nests are social in SW (this

147 study), nests are always non-social in Belfast (MID; Field et al. 2010) and Scotland

148 (SCO; this study). However, bees from Belfast (MID; Field et al. 2010) and Scotland

149 (SCO; this study) are socially plastic and may have social nests when moved to

150 more southerly sites. Bees sampled were expected to be foundresses based on 
151 collection date. We collected females by hand-netting in in late June in SCO, and in

152 May and early June in the SW, when all bees had fairly worn wings indicative of

153 several weeks of provisioning. In Belfast (MID) we excavated overwintering

154 foundresses in February.

\section{Transplant}

157 In addition to sampling from native populations, we collected bees that had been

158 transplanted from Scotland (SCO) to a site in the south-east (SE), the Knepp estate

159 in West Sussex (N 50 53' 60" W 021'36”; N = 47; see fig 1c). Buckets of soil were

160 embedded within a nest aggregation at the Scottish site during winter 2018-19, and

161 native foundresses subsequently nested in them during 2019. Their B1 offspring

162 then emerged in late summer 2019 and hibernated in the buckets. The buckets

163 containing hibernating Scottish bees were taken from Scotland to the south-east in

164 the spring of 2020, where they were re-embedded in the ground. SCO foundresses

165 that emerged were marked with a dot of enamel paint when they provisioned the B1

166 brood in the south-east. When the B1 emerged, they were marked with a different

167 colour of enamel paint. Each nest was marked with a numbered nail at the entrance.

168 This allowed us to distinguish fresh B1 females from the original foundresses and to

169 determine whether nests were solitary (with a single B1 female or original foundress

170 provisioning alone) or social (with multiple B1 females provisioning the nest). At the

171 end of the B1 provisioning phase we collected SCO foundresses (which had

172 emerged in Scotland and been transplanted to the SE) and their B1 offspring (which

173 had developed and emerged in the SE).

175 Specimen storage and preparation 
176 All specimens were stored in 95\% Ethanol until they were prepared for imaging. One

177 antenna was removed from each bee (whether it was the left or right was recorded)

178 and mounted on a JEOL aluminium stub (10mm dia $\times 10 \mathrm{~mm}$ high) using a PELCO

179 carbon conductive sticky tab (10 mm dia). Specimens were mounted dorsal side up.

180 Specimens were carbon coated using spectrograpically pure carbon.

181

182 Imaging

183 Mounted and carbon coated specimens were imaged using a TESCAN Vega SEM in

184 High Vacuum mode at $20.0 \mathrm{kV}$. The scan mode was set to resolution and the

185 magnification was $485 x$. Only the two distal segments (11 and 12), which have the

186 highest density of sensilla, were imaged. The length and area of each antennal

187 segment was measured during imaging and images of each antennal segment from

188 the SEM were saved in TIF format. 
A

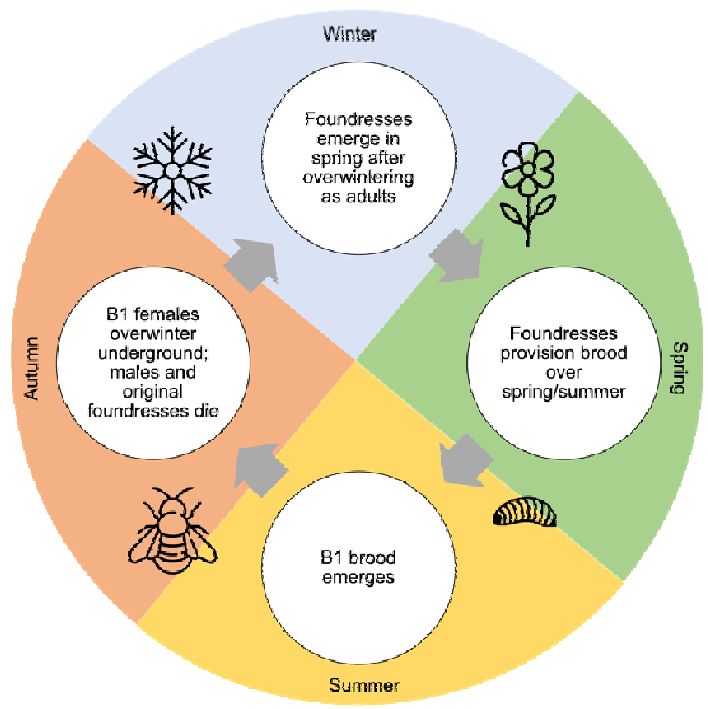

B

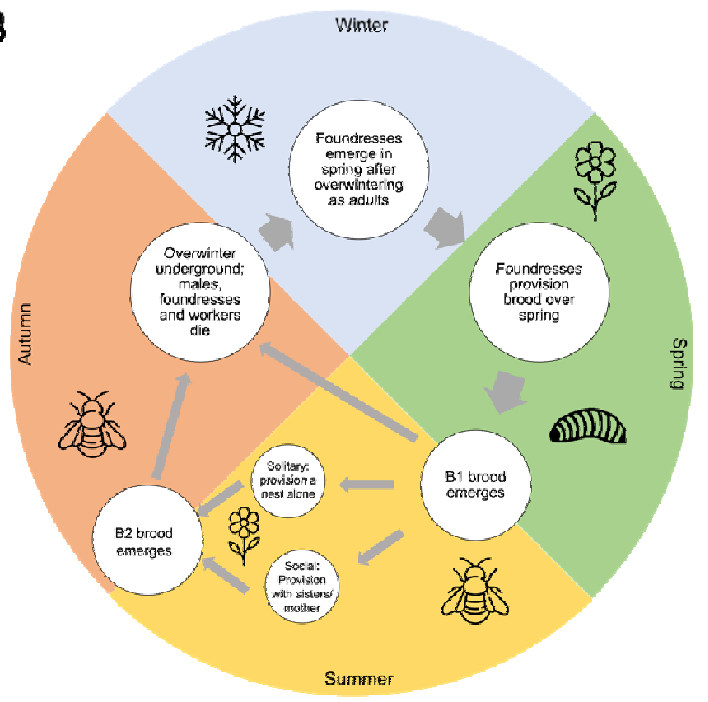

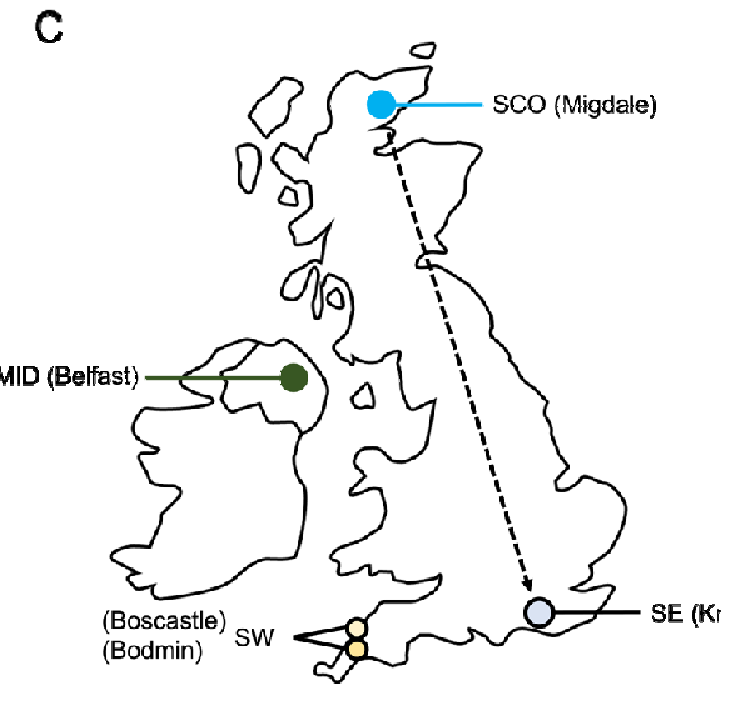

191

Figure 1 (A) univoltine lifecycle of Halictus rubicundus which prohibits social nesting (B) bivoltine lifecycle of Halictus rubicundus where sociality is possible as the $1^{\text {st }}$ brood (B1) can provision a second brood (B2). Note that in (B) the B1 females can either (i) overwinter and provision the following year as a solitary foundress (ii) provision a nest alone as a solitary foundress in the year that they emerge or (iii) provision the nest socially with their B1 sisters with a queen (their mother or a sister) in the year that they emerge. (C) Map depicting the sites where $H$. rubicundus females were studied. Dashed arrow represents the direction of the transplant experiment (SCO to SE). 


\section{Image scoring}

199 Eight distinct types of sensilla with overlapping functions have been characterised in

200 the Hymenoptera (Do Carmo Queiroz Fialho et al. 2014). Placoid sensilla are plate-

201 like structures that are involved in olfaction and chemoreception. Tricoid and

202 basiconic sensilla are hair-like projections with multiple sub-types that are used in

203 olfaction involving contact. Coeloconic, campaniform and ampulliform sensilla are

204 pore-like and are involved in sensing temperature, humidity and $\mathrm{CO}_{2}$ concentration

205 (Do Carmo Queiroz Fialho et al. 2014). For this study we grouped all sensilla types

206 into three structural/functional groups that allowed for repeatability in scoring: (i)

207 olfactory plate sensilla (sensilla placodea, fig 2), (ii) olfactory hair-type sensilla

208 (sensilla trichodea and basonica; fig 2) and (iii) temperature/humidity $/ \mathrm{CO}_{2}$ pore

209 sensilla (coeloconic/campaniform/ampulliform sensilla; fig 2).

211 Images of antennal segments 11 and 12 were scored using ImageJ software. For

212 each segment, three $50 \mu \mathrm{M} \times 50 \mu \mathrm{M}$ 'quadrats' were selected, the $\mathrm{X}$ and $\mathrm{Y}$

213 coordinates of which were derived by generating a random number using the excel

214 function RANDBETWEEN. Each quadrat was saved as a TIF image and the number

215 of sensilla types i and ii were counted. We counted sensilla type iii across the entire

216 segment as they are distributed unevenly on the surface of the antenna. In some

217 cases, bare patches with no sensilla were present on the surface of the antenna.

218 Any quadrats which fell on the bare areas were discarded and another area was

219 selected. We note that the scorer was not blind to the population of origin as the

220 same person was required to mount, image and score the antennae. 


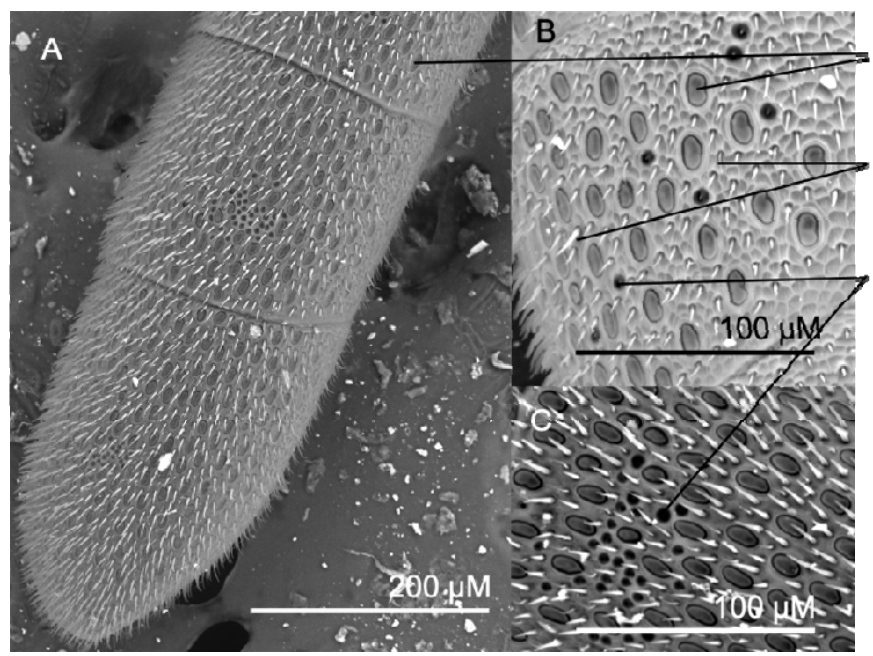

(i) Olfactory plates (placoid sensillae)

(ii) Olfactory hairs (basiconic/trichoid sensillae)

(iii) Temperature/humidity and $\mathrm{CO}_{2}$ sensitive pores (coeloconic, campaniform and ampulliform sensillae)

223 Figure 2 SEM image showing a Halictus rubicundus antenna tip. (A) shows the

224 distal 2 antennal segments (11 and 12) that were imaged, (B) and (C) show the

225 types (i, ii, and iii) of antennal sensilla that were counted. Scale is given in

$226 \mu \mathrm{M}$.

227 Analysis

228 Repeatability

229 Thirty-three of the 130 sampled antennae were scored a second time (by the same

230 person) for all sensilla types. The repeatability of image scoring was assessed using

231 the intra-class correlation coefficient, function ICC in the R package irr (Gamer et al,

232 2019).

234 Sensilla numbers

235 We used linear mixed models in the R package Ime4 (Bates et al. 2019) to test for

236 differences in the numbers of sensilla types (i-iii). For all models outlined below, the

237 response variable was total sensilla counted, either i) olfactory plates, total across 3

238 quadrats for each segment per individual; ii) olfactory hairs, total across 3 quadrats

239 for each segment per individual; or iii) temperature/humidity pores, total across each 
240 segment per individual. The package DHARMa was used to determine the most

241 appropriate error structure for all models (Gaussian) and to interpret residual plots

242 for lack of fit (Hartig, 2020).

245 Region, development site and social phenotype

246 To test whether bees from different regions have different numbers of sensilla we

247 included region as a fixed factor with 3 levels in LMMs: SW (Boscastle and Bodmin

248 combined; $\mathrm{N}=16$ individuals), MID (Belfast, Northern Ireland; $\mathrm{N}=19$ individuals)

249 and SCO (Migdale, Scotland, far north; $\mathrm{N}=15$ individuals).

251 We ran additional models to test whether sensilla density varies depending on where

252 bees complete their development (which may suggest developmental plasticity). To

253 do this we compared bees that developed in Scotland (SCO) with their offspring that

254 developed in the south-east after transplantation. LMMs included a fixed effect of

255 development site, with 2 levels: SCO (bees that emerged in Scotland and were

256 either collected there ( $N=15$ individuals, same individuals that were used in the

257 region models; or were moved to the south-east as adults, $N=4$ ) and SE (bees that

258 emerged as adults after immature development in the south-east, the B1 offspring of

259 the bees that were transplanted from Scotland to the south-east; $N=27$ ). Note that

$260 H$. rubicundus females mate before overwintering and so both the mother and father

261 of the B1 bees collected in the south-east originated in Scotland.

263 Additional LMMs were used to test whether B1 offspring collected in the SE (using

264 the same individuals used in the development site model for which nest phenotypes

265 were known, $\mathrm{N}=14$ ) had higher counts of sensilla if they were workers from social 
266 nests of transplanted females compared to those which left and started their own

267 solitary nests. Social nests had a queen and one or more workers, while solitary

268 nests had a single B1 foundress that produced offspring in the same year. For these

269 models we included nest phenotype as a fixed effect with 2 levels (social, $\mathrm{N}=6$ or

270 solitary, $\mathrm{N}=8$ ). We did not sample multiple individuals from the same nest, so did

271 not include nest as a random effect. We did not recover any queens from social

272 nests and so could not test for an effect of bee phenotype within social nests. We

273 also ran a model to test for effects of individual, rather than nest-level, phenotype

274 across social and solitary nests, using the same bees. For this analysis bees were

275 characterised as (1) a future reproductive (a B1 individual that had emerged in 2020

276 and did not provision that year; $\mathrm{N}=13$ ); (2) a worker (a B1 individual that

277 provisioned a nest containing a queen; $\mathrm{N}=7$ ); (3) a solitary foundress from 2019 (a

278 foundress that emerged in SCO in 2019 and laid eggs/provisioned a nest alone

279 without workers in the south-east); (4) a solitary foundress from 2020 (a foundress

280 that emerged in the B1 generation in 2020 in the SE and provisioned a nest alone; $\mathrm{N}$

$281=4)$.

282

283 Finally, we ran a model using the bees collected in the SE to test whether age-

284 related wear and tear reduces density of all 3 sensilla types. For these analyses age

285 was binary: bees were scored as fresh (newly emerged and had not provisioned a

286 nest; $\mathrm{N}=12$ ) or old (had provisioned a nest for several weeks $\mathrm{N}=16$ ).

288 All LMMs included antenna segment number (11 or 12) as a fixed factor. The

289 interaction effect between region/development type/social phenotype and segment

290 number was also fitted. We included a random effect of individual as two segments 
291 were imaged for each bee. Models were run using the function Imer in the R

292 package Ime4 (Bates et al, 2015).

293

\section{Results}

296 Repeatability and effects of age

297 Counts of all sensilla types were highly repeatable (Koo and Li 2016; ICC greater

298 than 0.85 for all; for a detailed summary see supplementary material table S1).

300 We also found no evidence that age-related wear and tear influences the variation in

301 sensilla density; there was no effect of age on density of any of the three types of

302 sensilla (type $\mathrm{i}: \mathrm{X}^{2}=0.25$, df $=1, \mathrm{p}=0.62$; type ii: $\mathrm{X}^{2}=0.01$, df $=1, \mathrm{p}=0.92$; type iii:

$\left.303 X^{2}=0.09, d f=1, p=0.76\right)$.

Differences between antennal segments

307 Olfactory plates (type i) and olfactory hairs (type ii) were found in greater numbers on

308 the most distal antennal segment, segment 12, while hygro/thermoreceptors (type iii)

309 were found in higher numbers on segment 11. There were no interaction effects

310 between segment number and region (table 1).

312 Region

313 There was a significant effect of region on the counts of type ii (olfactory hairs) and iii

314 (thermo/hygroreceptors) sensilla, but not type i (olfactory plate receptors; see table

315 1, figure 3a-c). Pairwise tests show that bees from mid-latitude (MID; Belfast; $N=19$ ) 
316 had significantly more olfactory hairs (type ii) than bees collected from the far north

317 (Scotland; $N=30 ; p=0.03$; figure $3 b)$, whereas bees from the south-west $(N=16)$ did

318 not differ from MID $(N=32 ; p=0.06)$ or Scottish $(N=15 ; p=0.93)$ bees. Bees from

319 SCO and MID had more thermo/hygro (type iii) receptors than SW bees $(p<0.05$;

320 figure 3c). Bees from the south-west had the most olfactory plate sensilla (type i) but

321 this was not statistically significant (figure 3a).

322

323 Table 1 LMM results showing effect of region on antennal sensilla counts across

324 segments using type II sums of squares ( $p$-values for main effects are calculated

325 independent from interaction effects which in all cases are non-significant).

\begin{tabular}{|c|c|c|c|c|}
\hline Sensilla type & Effect & $\mathrm{X}^{2}$ & df & $\mathbf{P}$ \\
\hline "Type i) olfactory plates & $\begin{array}{l}\text { Region } \\
\text { Segment } \\
\text { Region*Segment }\end{array}$ & $\begin{array}{l}2.31 \\
19.48 \\
0.45\end{array}$ & $\begin{array}{l}2 \\
1 \\
2\end{array}$ & $\begin{array}{l}0.31 \\
1.01 \times 10^{-5} \\
0.80\end{array}$ \\
\hline Type ii) olfactory hairs & $\begin{array}{l}\text { Region } \\
\text { Segment } \\
\text { Region*Segment }\end{array}$ & $\begin{array}{l}7.81 \\
41.74 \\
2.70\end{array}$ & $\begin{array}{l}2 \\
1 \\
2\end{array}$ & $\begin{array}{l}0.02 \\
1.04 \times 10^{-10} \\
0.26\end{array}$ \\
\hline Type iii) thermo/hygro-receptive & $\begin{array}{l}\text { Region } \\
\text { Segment } \\
\text { Region*Segment }\end{array}$ & $\begin{array}{l}9.14 \\
19.17 \\
0.35\end{array}$ & $\begin{array}{l}2 \\
1 \\
2\end{array}$ & $\begin{array}{l}0.01 \\
1.20 \times 10^{-5} \\
0.84\end{array}$ \\
\hline
\end{tabular}




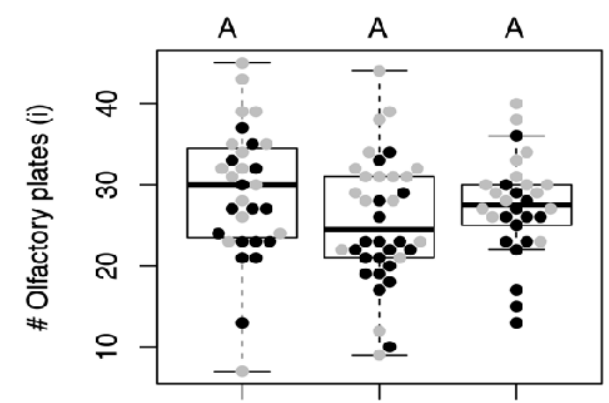

(a)

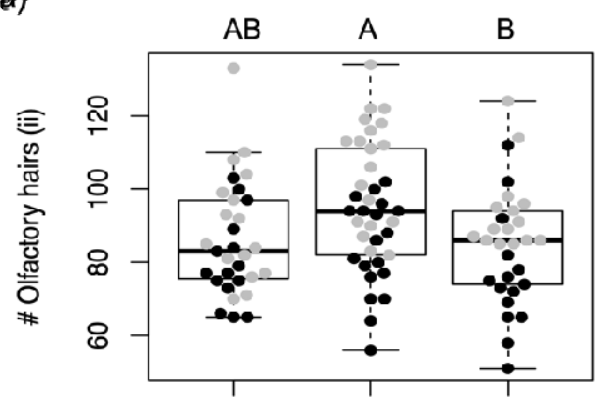

(b)

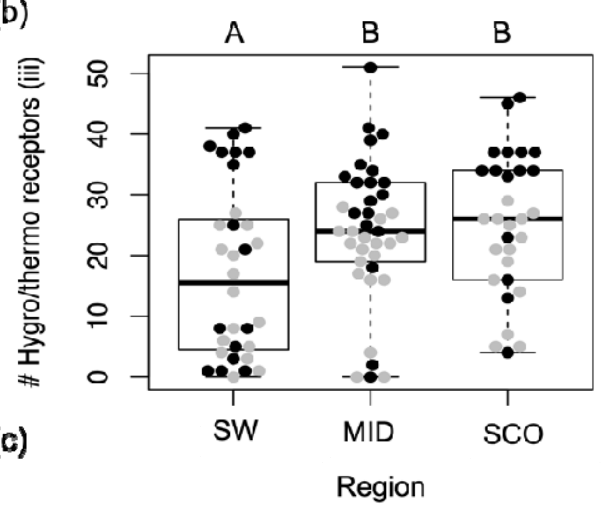

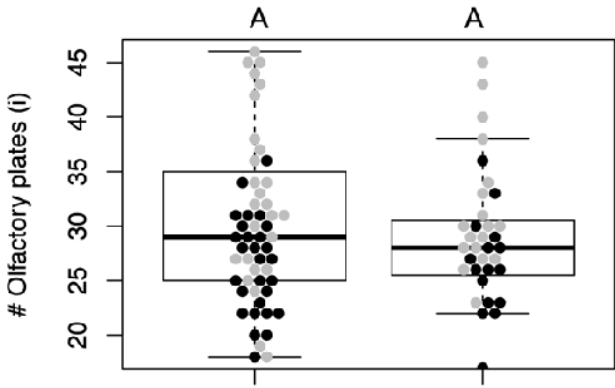

(d)

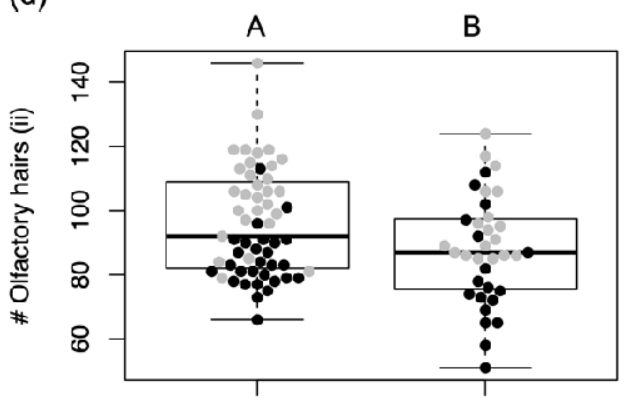

(e)

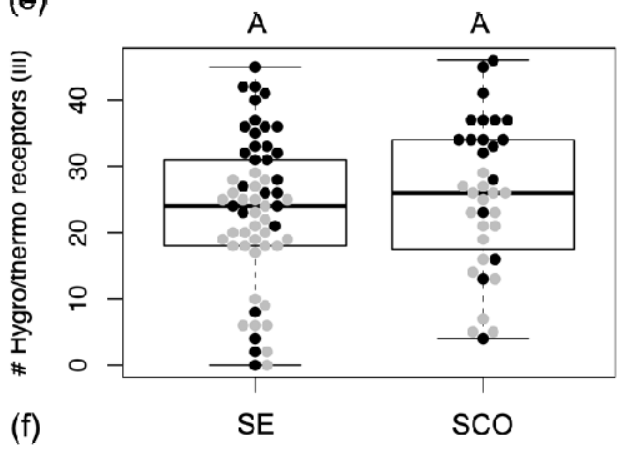

Development site

329 Figure 3 Numbers of (a) and (d) olfactory plates, i; (b) and (e) olfactory hairs, ii; and

330 (c) and (f) hygro/thermoreceptive pores, iii, for Halictus rubicundus across: a-c three

331 sampled regions: SW (South-west; mostly social), MID (Belfast; solitary) and SCO

332 (Scotland; solitary); d-e for Halictus rubicundus originating from Scotland and

333 collected after either developing as larvae in Scotland (SCO) or after developing as

334 larvae at the transplanted site in the south-east (SE). Different uppercase letters over

335 bars indicate significantly different counts of sensilla. Black points represent sensilla

336 counts on segment 11 and grey points on segment 12. Box plots show median and

337 quartiles across segments 11 and 12. 
bioRxiv preprint doi: https://doi.org/10.1101/2022.01.29.478030; this version posted February 3, 2022. The copyright holder for this preprint

(which was not certified by peer review) is the author/funder, who has granted bioRxiv a license to display the preprint in perpetuity. It is made available under aCC-BY-NC-ND 4.0 International license.

\section{Development site}

339 The density of olfactory hairs (type ii) varied according to where bees originating

340 from Scotland spent their immature development (table 2; figure 3d-e). Offspring of

341 transplanted bees which developed in the south-east $(\mathrm{N}=27)$ had more olfactory

342 hairs (type ii, $p=0.01$ ) than conspecifics that developed in their natal Scottish site

$343(\mathrm{~N}=19$; fig 3e). A similar trend was seen in olfactory plates (I; fig $3 \mathrm{~d}$ ) but this was not

344 statistically significant $(p=0.06)$. There was no effect of origin on

345 thermo/hygroreceptor numbers (iii; fig 3f). 
Table 2 LMM results showing effect of origin of emergence on antennal sensilla counts across segments ( $p$-values for main effects

349 are calculated independent from interaction effects which in all cases are non-significant).

350

\begin{tabular}{l|lccc}
\hline Sensilla type & Effect & \multicolumn{1}{c}{$\mathbf{X}^{2}$} & df & P \\
\hline Type i) olfactory plates & Development site & 3.44 & 1 & 0.06 \\
& Segment & 34.82 & 1 & $3.6 \times 10^{-9}$ \\
& Development site *Segment & 0.61 & 1 & 0.43 \\
\hline Type ii) olfactory hairs & Development site & 6.41 & 1 & 0.01 \\
& Segment & 61.35 & 1 & $4.79 \times 10^{-15}$ \\
& Development site *Segment & 1.57 & 1 & 0.21 \\
\hline Type iii) thermo/hygroreceptive & Development site & 0.74 & 1 & 0.39 \\
& Segment & 33.25 & 1 & $8.12 \times 10^{-9}$ \\
& Development site *Segment & 0.15 & 1 & 0.69 \\
\hline
\end{tabular}




\section{Sociality}

354 B1 workers from social nests $(\mathrm{N}=6)$ and solitary $\mathrm{B} 1$ females that founded new nests

355 alone $(\mathrm{N}=8)$ had equivalent numbers of all 3 sensilla types (i-iii, see table 3; fig 4a-c)

356 and there were no interactions between nest phenotype and antenna segment

357 number. There was some suggestion that solitary bees had higher numbers of

358 olfactory plates (type i), but this was not statistically significant $(p=0.07)$. Similarly

359 there were no differences in numbers of any sensilla types across different individual

360 phenotypes (B1 future reproductive emerged in 2020 in SE and did not provision that

361 year, will overwinter, $N=13$; $B 1$ worker emerged in 2020 in the $S E, N=7$; B1

362 solitary foundress that emerged 2019 in SCO and provisioned in the SE in $2020, \mathrm{~N}=$

363 4; and B1 solitary foundress emerged and provisioned in 2020 in SE, N = 4; see

364 table 4; figure 4d-e). These results were the same if B1 solitary foundresses from

3652019 (that developed and emerged in SCO) were excluded (see archived code and

366 data; $\underline{\text { https://github.com/DrBecky-B/Bee.Antennae). }}$.

368 Table 3 LMM results showing effect of nest phenotype (social/solitary) on antennal

369 sensilla counts across segments ( $p$-values for main effects are calculated

370 independent from interaction effects which in all cases are non-significant).

\begin{tabular}{l|lrrr}
\hline Sensilla type & Effect & $\mathbf{X}^{2}$ & $\mathbf{d f}$ & $\mathbf{P}$ \\
\hline \hline Type i) olfactory plates & Nest phenotype & 2.91 & 1 & 0.08 \\
& Segment & 11.80 & 1 & 0.0005 \\
& Nest phenotype*Segment & 1.08 & 1 & 0.30 \\
& Nest phenotype & 0.08 & 1 & 0.78
\end{tabular}




\begin{tabular}{l|lrrr} 
& Segment & 42.03 & 1 & $8.98 \times 10^{-11}$ \\
& Nest phenotype*Segment & 1.29 & 1 & 0.26 \\
\hline Type iii) thermo/hygroreceptive & Nest phenotype & 0.29 & 1 & 0.59 \\
& Segment & 33.08 & 1 & $8.86 \times 10^{-9}$ \\
& Nest phenotype*Segment & 0.10 & 1 & 0.75 \\
& & & & \\
\hline
\end{tabular}

373 Table 4 LMM results showing effect of bee phenotype (future

374 reproductive/worker/solitary foundress 2019 and solitary foundress 2020) on

375 antennal sensilla counts across segments ( $p$-values for main effects are calculated

376 independent from interaction effects which in all cases are non-significant).

377

\begin{tabular}{l|lccc}
\hline Sensilla type & Effect & $\mathbf{X}^{2}$ & $\mathbf{d f}$ & $\mathbf{P}$ \\
\hline \hline Type i) olfactory plates & Bee phenotype & 1.51 & 3 & 0.67 \\
& Segment & 22.34 & 1 & $2.29 \times 10^{-6}$ \\
& Bee phenotype*Segment & 1.81 & 3 & 0.61 \\
& Bee phenotype & 1.24 & 3 & 0.74 \\
\hline Type ii) olfactory hairs & Segment & 42.03 & 1 & $8.33 \times 10^{-11}$ \\
& Bee phenotype*Segment & 0.85 & 3 & 0.84 \\
& Bee phenotype & 3.39 & 3 & 0.34 \\
& Segment & 30.18 & 1 & $3.95 \times 10^{-8}$ \\
& Bee phenotype*Segment & 2.26 & 3 & 0.52 \\
\hline
\end{tabular}




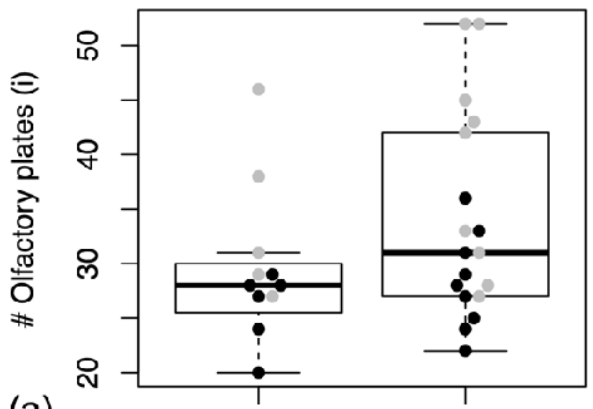

(a)

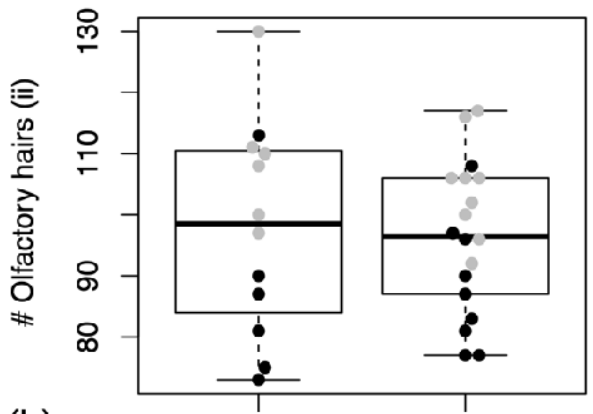

(b)

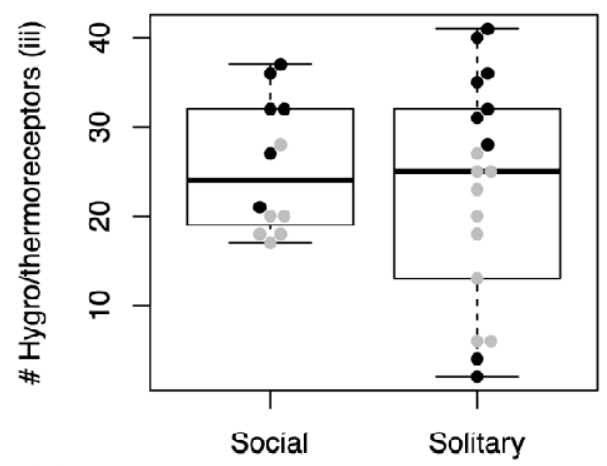

(c)

Nest phenotype

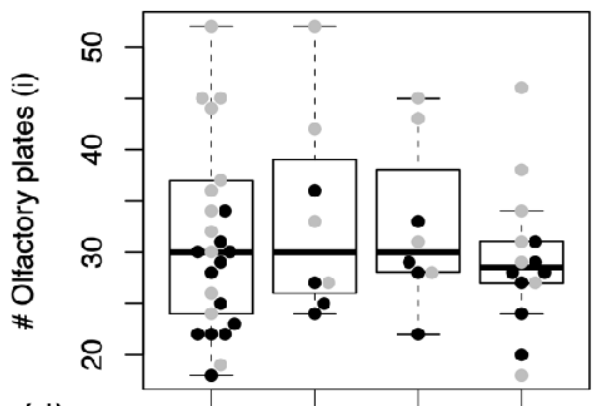

(d)

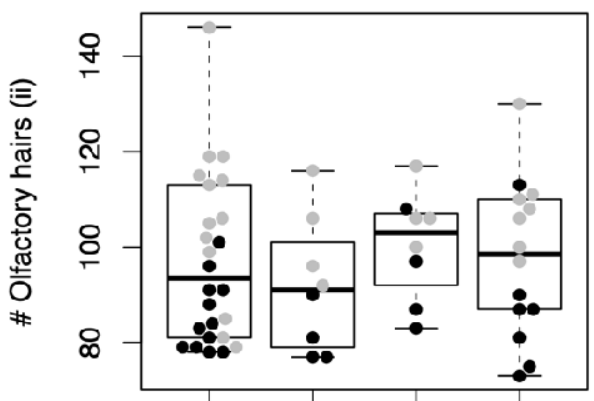

(e)

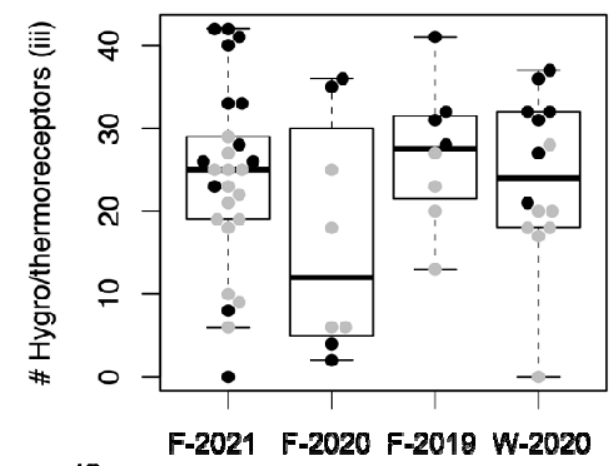

$(f)$

Figure 4 Numbers of (a) and (d) olfactory plates, i; (b) and (e) olfactory hairs, ii; and

383 (c) and (f) hygro/thermoreceptive pores, iii; for Halictus rubicundus from Scotland

384 collected from (a-c) social and solitary nests and according to individual phenotype

385 (d-f) after being transplanted to the south-east in 2020. For figures 4d-4f: F-2021

386 female that emerged in the SE in 2020 but did not provision that year; F-2020 female

387 that emerged in the SE in 2020 and provisioned a nest as a solitary foundress; F-

3882019 female that emerged in SCO in 2019 and provisioned a nest as a solitary 
389 foundress in 2020; W-2020 female that emerged in the SE in 2020 and provisioned a

390 social nest in the same year as a worker. Black points represent sensilla counts on

391 segment 11 and grey points on segment 12. Box plots show median and quartiles

392 across segments 11 and 12. There were no significant differences in counts of any

393 sensilla type across the groups.

\section{Discussion}

397 The social Hymenoptera have contributed much to our understanding of the

398 proximate and ultimate factors that underlie the evolution of sensory systems.

399 Attention has focussed chiefly on how sociality has imposed selection to optimise

400 olfactory communication, enhancing social cohesion through nest-mate recognition

401 and supporting caste polyphenisms (Wcislo 1997; Ozaki et al. 2005; Spaethe et al.

402 2007; Renner and Nieh 2008; Riveros and Gronenberg 2010; Gill et al. 2013; Couto

403 et al. 2017; Gru $\square$ ter et al. 2017; Elgar et al. 2018). In the current study we measured

404 sensilla density in the socially plastic sweat bee Halictus rubicundus. We found that

405 when bees were transplanted from Scotland, where they are solitary, to the south

406 where they can be social, their offspring had higher densities of olfactory hairs.

407 These results suggest that the density of olfactory hairs may, like sociality, be

408 phenotypically plastic in $H$. rubicundus. We also found evidence for between-region

409 differences in the density of basiconic/trichoid olfactory hairs (and

410 hygro/thermoreceptive sensilla) for untransplanted bees, with mid-latitude bees

411 having higher densities than more northerly Scottish bees. Differences were not

412 perfectly correlated with the expected degree of sociality, however, because bees

413 from the south-west did not differ from mid-latitude or Scottish bees. 
415 The results from our transplant experiment suggest that olfactory hair density may be

416 phenotypically plastic, and may vary depending on the conditions that bees

417 experience during development. When Scottish bees were transplanted to the south-

418 east, their offspring that developed there (where air and soil temperatures in June

419 and July are $2-5^{\circ} \mathrm{C}$ warmer than their native site; table S2) had greater densities of

420 trichoid/basiconic hairs. In this scenario, warmer temperatures during development,

421 rather than social phenotype, lead to greater densities of olfactory hairs. A similar

422 pattern is seen in the parasitoid wasp Trichogramma; when males develop under

423 colder temperatures they have reduced numbers of basiconic hairs (Pinto et al.

424 1989). A direct response to temperature might explain why untransplanted

425 foundresses from the south-west, where bees are often social, but temperatures are

426 not as high as in the south-east, did not have higher basiconic hair densities than

427 non-social populations (Fig. 3).

429 In addition to plasticity within a population, we also found evidence that olfactory hair

430 density (type ii, basiconic/trichoid sensilla) varies across regional populations in $H$.

431 rubicundus. In contrast we saw no differences in the densities of placoid (plate-like,

432 type i) olfactory sensilla across regions. This may relate to the function of these

433 receptor types. Basiconic/trichoid hairs respond to contact with the CHCs of other

434 individuals, and so are likely to be required for nest-mate recognition and

435 communication, while placoid plates are thought to be involved in longer range

436 olfaction to detect food and hosts (Ozaki et al. 2005; McKenzie et al. 2016; Couto et

437 al. 2017; Pask et al. 2017). We know of no clinal variation in diet breadth in this 
438 species (although this remains to be rigorously studied), which fits with the pattern

439 we see here.

440

441 Bees collected from Belfast at a mid-latitude had the highest density of olfactory hair-

442 like sensilla (type ii), higher than bees from Scotland (450km north of Belfast) but

443 statistically equivalent to bees collected in the south-west. We predicted that $H$.

444 rubicundus collected further south would have the greatest densities of olfactory

445 sensilla to support social communication between nestmates (Wittwer et al. 2017;

446 Elgar et al. 2018). In the south, summers are typically warmer and longer and a

447 higher proportion of the population is expected to exhibit social behaviour more

448 regularly. While we did see regional differences in olfactory sensilla density, bees

449 from the south-west did not have the highest densities as we would have predicted

450 based on clines in sociality. The regional differences we saw may be related to

451 developmental plasticity, which could limit the scope for fixed population level

452 differences to evolve in the predicted direction. Longitudinal studies of these same

453 populations and additional, reciprocal transplant experiments (from south to north)

454 would help to elucidate the extent to which genetically fixed differences in olfactory

455 hair density and plastic expression contribute to the population level differences we

456 saw in this trait.

457

458 We also found that the density of sensilla (type iii) involved in the perception of

459 humidity, temperature and $\mathrm{CO}_{2}$ varies across regions, but unlike olfactory hairs this

460 does not appear to be plastic. Bees from a mid-latitude and the north of Scotland

461 (Belfast and Scotland) have more thermo/hygro receptive sensilla than bees from the

462 south-west (400 km south of Belfast and $850 \mathrm{~km}$ south of the Scottish site). The 
463 density of these sensilla does not appear to be plastic as it was not influenced by

464 where Scottish bees developed or their social phenotype. This pattern may be a

465 result of a more extreme, variable climate in the north, which leads to consistent

466 selection for higher densities of thermo/hygro receptors. Sweat bees including $H$.

467 rubicundus are highly sensitive to temperature and rain. Flight activity is constrained

468 by low ambient temperatures, lack of sunlight and rainfall (Potts and Wilmer 1997).

469 In the north, bees experience colder ambient temperatures and greater rainfall. Bees

470 with more of these receptors may be more sensitive to current and oncoming

471 weather conditions, so that they have reduced mortality and improved foraging

472 based on the climate. The potentially severe fitness consequences of incorrect

473 perception of climatic cues may explain the lack of plasticity in the number of

474 thermo/hygro receptors if selection has a strong and canalising effect on this trait.

475

476 Our results add a new dimension to the growing body of evidence that

477 developmental temperature may contribute to adaptations which support sociality in

478 the Hymenoptera. While previous studies suggest that temperatures experienced by

479 developing larvae contribute to individual differences in social phenotype (i.e. caste

480 polyphenism: Czekońska and Tofilski 2020; Becher et al. 2009; the development of

481 status badges: Green et al. 2012; memory formation: Jones et al. 2005 and olfactory

482 learning: Anton and Rossler 2021), sensilla density in the socially plastic $H$.

483 rubicundus may be a more general response to the environment that is not directly

484 related to the social phenotype of the nest or individual (i.e. a worker, solitary

485 foundress or queen). Scottish bees that developed in the south-east had more

486 olfactory hairs than their conspecifics that emerged in Scotland irrespective of their

487 caste or nest phenotype. 
489 In the Halictidae, Wittwer et al (2017) found that halictid bee species that had

490 reverted back to solitary nesting from a state of sociality had reduced olfactory hair

491 density compared to social species and ancestrally solitary species. They suggest

492 that this is because dense olfactory sensilla are a pre-adaptation that facilitates the

493 evolution of sociality and may contribute to the repeated evolutionary transitions to

494 sociality seen in the halictid bees. Our results expand on this, suggesting that

495 olfactory hair density may also be phenotypically plastic. More broadly, plasticity in

496 traits such as this might contribute to the evolutionary lability of sociality in the

497 Halictidae and in the Hymenoptera, acting alongside social plasticity in the

498 hymenopteran ancestor to provide the 'flexible stem' which allowed for repeated

499 evolutionary transitions to obligate sociality across the order (West-Eberhard 2003;

500 Wittwer et al. 2017).

501

502 Acknowledgements

503 Many thanks to Gavyn Rollinson and Sharon Uren for SEM training and technical

504 support. This work is part of a project that received funding from the European

505 Research Council (ERC) under the European Horizon's 202 research and innovation

506 programme (grant agreement No. 695744).

507

508 Conflict of interest

509 The authors have no conflict of interests to report.

510

511 Ethics 
512 This research adheres to ethical codes of practice at the University of Exeter. No

513 vertebrates were used in this research. Bee antenna samples were taken from living

514 and dead stored specimens. Handling during antenna removal of live specimens was

515 done as quickly as possible to minimize stress to individuals. Bees frequently lose

516 parts of and whole antennae in nature and we did not see any negative effects on

517 the survival or provisioning behaviour of live sampled individuals compared to intact

518 bees. The sample sizes reported were considered appropriate to maximize statistical

519 power while reducing the number of individuals involved in the experiments.

520 Individuals were sampled from large populations > 500 individuals and numbers

521 taken did not pose a threat to the persistence of these populations.

524 Data accessibility

525 All code and data are archived on Github and can be accessed here:

526 https://github.com/DrBecky-B/Bee.Antennae

\section{References}

529 Andersson, M. 1984. The evolution of eusociality. Annual review of Ecology, $530 \quad$ Evolution and Systematics 15:165-189.

531 Anton, S., and W. Rössler. 2021. Plasticity and modulation of olfactory circuits in $532 \quad$ insects. Cell and Tissue Research 383:149-164.

533 Babu, M. 2019. Antennal sensilla of the weaver ant Oecophylla smaragdina (F.) $534 \quad$ males and females sense differently. Indian Journal of Entomology 81:418$535 \quad 422$. 
536 Bates, D., Maechler, M., Bolker, B and W. Walker. 2015. Fitting Linear Fixed-Effects

$537 \quad$ Models using Ime4. Journal of statistical software 67:1-48

538 Becher, M. A., H. Scharpenberg, and R. F. A. Moritz. 2009. Pupal developmental

539 temperature and behavioral specialization of honeybee workers (Apis

540 mellifera L.). Journal of Comparative Physiology A: Neuroethology, Sensory,

$541 \quad$ Neural, and Behavioral Physiology 195:673-679.

542 Boughman, J. W. 2002. How sensory drive can promote speciation. Trends in

$543 \quad$ Ecology and Evolution 17:571-577.

544 Charnov, E. L. 1978. Evolution of eusocial behavior: Offspring choice or parental

545 parasitism? Journal of Theoretical Biology 75:451-465.

546 Couto, A., A. Mitra, D. Thiéry, F. Marion-Poll, and J. C. Sandoz. 2017. Hornets have

547 it: A conserved olfactory subsystem for social recognition in hymenoptera?

$548 \quad$ Frontiers in Neuroanatomy 11:1-12.

549 Czekońska, K., and A. Tofilski. 2020. Body mass of honey bee drones developing in

$550 \quad$ constant and in changing temperatures. Apidologie 51:510-518.

551 Dobberfuhl, A. P., J. F. P. Ullmann, and C. A. Shumway. 2005. Visual acuity,

552 environmental complexity, and social organization in African cichlid fishes.

$553 \quad$ Behavioral Neuroscience 119:1648-1655.

554 Do Carmo Queiroz Fialho, M., C. P. Guss-Matiello, J. C. Zanuncio, L. A. Oliveira

555 Campos, and J. E. Serrão. 2014. A comparative study of the antennal sensilla

556 in corbiculate bees. Journal of Apicultural Research 53:392-403.

557 Elgar, M. A., D. Zhang, Q. Wang, B. Wittwer, H. T. Pham, T. L. Johnson, C. B.

$558 \quad$ Freelance, et al. 2018. Insect antennal morphology: The evolution of diverse

559 solutions to odorant perception. Yale Journal of Biology and Medicine 91:457-

560469. 
561 Field, J., R. J. Paxton, A. Soro, and C. Bridge. 2010. Cryptic plasticity underlies a

562 major evolutionary transition. Current Biology 20:2028-2031.

563 Field, J., R. Paxton, A. Soro, P. Craze, and C. Bridge. 2012. Body size, demography

564 and foraging in a socially plastic sweat bee: A common garden experiment.

$565 \quad$ Behavioral Ecology and Sociobiology 66:743-756.

566 Galvani, G. L., R. A. González-Vaquero, C. Guerra-Navarro, and B. P. Settembrini.

567 2017. Antennal sensilla of cleptoparasitic and non-parasitic bees in two

568 subfamilies of Apidae. Apidologie 48:437-449.

569 Gamer, M., Lemon, J., Fellows, L, and P. Singh. 2019. r: Various Coefficients of

$570 \quad$ Interrater Reliability and Agreement. R package version 0.84.1.

571 https://CRAN.R-project.org/package=irr

572 Gibbs, J., S. G. Brady, K. Kanda, and B. N. Danforth. 2012. Phylogeny of halictine

573 bees supports a shared origin of eusociality for Halictus and Lasioglossum

574 (Apoidea: Anthophila: Halictidae). Molecular Phylogenetics and Evolution

$575 \quad 65: 926-939$.

576 Gill, K. P., E. van Wilgenburg, D. L. Macmillan, and M. A. Elgar. 2013. Density of

577 antennal sensilla influences efficacy of communication in a social insect.

$578 \quad$ American Naturalist 182:834-840.

579 Green, J. P., C. Rose, and J. Field. 2012. The role of climatic factors in the

580 expression of an intrasexual signal in the paper wasp Polistes dominulus.

$581 \quad$ Ethology 118:766-774.

582 Groom, S. V. C., and S. M. Rehan. 2018. Climate-mediated behavioural variability in 583 facultatively social bees. Biological Journal of the Linnean Society 125:165$584 \quad 170$. 
585 Grüter, C., F. H. I. D. Segers, L. L. G. Santos, B. Hammel, U. Zimmermann, and F.

586 S. Nascimento. 2017. Enemy recognition is linked to soldier size in a

587 polymorphic stingless bee. Biology Letters 13: 20170511.

588 Harrison, X. A. 2014. Using observation-level random effects to model

589 overdispersion in count data in ecology and evolution. PeerJ e616.

590

591 Hartig, F. 2020. DHARMa: Residual Diagnostics for Hierarchical (Multi-Level/Mixed)

592 Regression Models (2017). R package version 0.1, 5.

593 Jones, B. M., C. J. Kingwell, W. T. Wcislo, and G. E. Robinson. 2017. Caste-biased

594 gene expression in a facultatively eusocial bee suggests a role for genetic

595 accommodation in the evolution of eusociality. Proceedings of the Royal

$596 \quad$ Society B: Biological Sciences 284:20162228.

597 Jones, J. C., P. Helliwell, M. Beekman, R. Maleszka, and B. P. Oldroyd. 2005. The

598 effects of rearing temperature on developmental stability and learning and 599 memory in the honey bee, Apis mellifera. Journal of comparative physiology.

600 A, Neuroethology, sensory, neural, and behavioral physiology 191:1121-

$601 \quad 1129$.

602 Koo, T. K., and M. Y. Li. 2016. A Guideline of Selecting and Reporting Intraclass

603 Correlation Coefficients for Reliability Research. Journal of Chiropractic

$604 \quad$ Medicine 15:155-163.

605 Korner-Nievergelt, F., Roth, T., von Felten, S., Guelat, J., Almasi, B., and P. Korner-

606 Nievergelt. 2015. Bayesian Data Analysis in Ecology using Linear Models with

607 R, BUGS and Stan. Elsevier.

608 McKenzie, S. K., Fetter-Pruneda, I., Ruta, V., and Kronauer, D. J. C. 2016.

609 Transcriptomics and neuroanatomy of the clonal raider ant implicate an 
610

612

expanded clade of odorant receptors in chemical communication. Proceedings of the National Academy of Sciences 113: 14091-14096.

Ozaki, M., A. Wada-Katsumata, K. Fujikawa, M. Iwasaki, F. Yokohari, Y. Satoji, T. Nisimura, et al. 2005. Behavior: Ant nestmate and non-nestmate discrimination by a chemosensory sensillum. Science 309:311-314.

Pask, G. M., Slone, J. D., Millar, J. G., Das, P., Moreira, J. A., Zhou, X., Bello, J., Berger, S. L., Bonasio, R., Desplan, C., Reinberg, D., Liebig, J., Zwiebel, L. J., and Ray, A. 2017. Specialized odorant receptors in social insects that detect cuticular hydrocarbon cues and candidate pheromones. Nature Communications 8: 297.

Pinto, J. D., R. K. Velten, G. R. Platner, and E. R. Oatman. 1989. Phenotypic plasticity and taxonomic tharacters in Trichogramma (Hymenoptera: Trichogrammatidae). Annals of the Entomological Society of America 82:414425.

Potts, S. G., and P. Willmer. 1997. Abiotic and biotic factors influencing nest-site selection by Halictus rubicundus, a ground-nesting halictine bee. Ecological Entomology 22:319-328.

Purcell, J. 2011. Geographic patterns in the distribution of social systems in terrestrial arthropods. Biological Reviews 86:475-491.

Renner, M. A., and J.C. Nieh. 2008. Bumble bee olfactory information flow and contact-based foraging activation. Insects Socieaux 55: 417-424.

Riveros, A. J., and W. Gronenberg. 2010. Sensory allometry, foraging task specialization and resource exploitation in honeybees. Behavioral Ecology and Sociobiology 64:955-966. 
634 Spaethe, J., A. Brockmann, C. Halbig, and J. Tautz. 2007. Size determines antennal

635 sensitivity and behavioral threshold to odors in bumblebee workers.

$636 \quad$ Naturwissenschaften 94:733-739.

637 Wcislo, W. T. 1995. Sensilla numbers and antennal morphology of parasitic and non-

638 parasitic bees (Hymenoptera $\square$ : Apoidea). International Journal of Insect

639 Morphology and Embryology 24:63-81.

640 Wcislo, W. T. 1997. Social interactions and behavioral context in a solitary bee

641 Lasioglossum (Dialictus) figueresi (Hymenoptera, Halictidae). Insects Sociaux

$642 \quad$ 44: 199-208.

643 West-Eberhard, M.J. 2003. Developmental plasticity and evolution. Oxford University

$644 \quad$ Press, Oxford

645 Wittwer, B., A. Hefetz, T. Simon, L. E. K. Murphy, M. A. Elgar, N. E. Pierce, and S.

646 D. Kocher. 2017. Solitary bees reduce investment in communication

647 compared with their social relatives. Proceedings of the National Academy of

648 Sciences of the United States of America 114:6569-6574.

649 